Arq. Bras. Med. Vet. Zootec., v.67, n.1, p.211-220, 2015

\title{
Levedura seca integral na alimentação de vacas lactantes
}

\author{
[Dry yeast for lactating dairy cows] \\ D.R. Freitas ${ }^{1}$, J.M.S. Campos $^{2}$, M.I. Marcondes ${ }^{3}$, S.C. Valadares Filho ${ }^{3}$, M.O. Franco ${ }^{4}$, \\ E.C. Martins ${ }^{5}$, B.M.C. Rodrigues ${ }^{5}$, A.S. Oliveira ${ }^{6}$ \\ ${ }^{1}$ Aluna de pós-graduação - Universidade Federal de Minas Gerais - UFMG - Belo Horizonte, MG \\ ${ }^{2}$ Universidade Federal Rural de Pernambuco - UFRPE - Guaranhuns, PE \\ ${ }^{3}$ Universidade Federal de Viçosa - UFV - Viçosa, MG \\ ${ }^{4}$ Aluna de pós-graduação - Universidade Federal de Viçosa - UFV - Viçosa, MG \\ ${ }^{5}$ Aluno de graduação - Universidade Federal de Viçosa - UFV - Viçosa, MG \\ ${ }^{6}$ Universidade Federal do Mato Grosso - UFMT - Sinop, MT \\ RESUMO
}

\begin{abstract}
Os efeitos da inclusão de levedura seca de cana-de-açúcar (Saccharomyces cerevisiae) na dieta de vacas lactantes foram avaliados com base no fornecimento de quatro dietas constituídas de diferentes níveis de substituição do farelo de soja pela levedura de cana-de-açúcar $(0,00 ; 0,33 ; 0,67$ e 1,00kg/kg de MS). O delineamento utilizado foi o quadrado latino $4 \times 4$. Não houve efeito dos tratamentos sobre o consumo de MS, MO, EE, FDNi e NDT, porém ocorreu redução linear no consumo de PB e FDNcp e aumento do consumo de CNF. Diferenças estatísticas não foram verificadas para os coeficientes de digestibilidade aparente da MS, MO, PB, CNF e NDT; no entanto os coeficientes do FDNcp e do EE decresceram linearmente. Não foi observado efeito sobre a produção e eficiência de síntese microbiana, utilização dos componentes nitrogenados e produção e composição do leite. Conclui-se que a levedura seca pode substituir $100 \%$ o farelo de soja na alimentação de vacas lactantes.
\end{abstract}

Palavras-chave: ingestão, performance, Saccharomyces cerevisiae, vacas leiteiras

\begin{abstract}
The effects of the inclusion of sugar cane dry yeast (Saccharomyces cerevisiae) in dairy cows feeding were evaluated based on the provision of four different diets with increasing proportions of sugar cane dry yeast $(0.00 ; 0.33 ; 0.67$ and $1.00 \mathrm{~kg} / \mathrm{kg}$ of DM). The design adopted for this research was the latin square, $4 \times 4$. It was observed that the levels of yeast inclusion did not affect the intake of DM, OM, EE, $N D F i$ and TDN. However, the CP and NDFcp intake decreased linearly, whereas the NFC intake increased linearly with the increasing levels of yeast. No effect on the digestibility coefficient of DM, OM, $C P, N D F c p$ and NCF was observed. Nevertheless, the EE digestibility coefficient linearly decreased with the yeast inclusion in the experimental diets. There was no treatment effect on the production and efficiency of microbial synthesis, usage of nitrogenous components, as well as milk production and composition. It was concluded that the dried yeast can fully replace the soybean meal in diets of dairy cows.
\end{abstract}

Keywords: dairy cows, digestibility, intake, performance, Saccharomyces cerevisiae

\section{INTRODUÇÃO}

A levedura seca de cana-de-açúcar (Saccharomyces cerevisiae) é um coproduto proveniente do creme de levedura excedente do processo de fermentação do etanol de cana-deaçúcar, que, depois de centrifugado e separado do vinho, é seco por spray dried. Apresenta entre 5 e 15 bilhões de células inativas por grama de produto, as quais possuem maior proporção de carboidratos em relação à proteína e parede

Recebido em 26 de setembro de 2013

Aceito em 11 de setembro de 2014

E-mail: deniseribeirof@yahoo.com 
celular espessa, insolúvel e muito resistente à ação das enzimas do trato gastrointestinal (Santos, 2009). O teor de proteína bruta é de aproximadamente $410 \mathrm{~g} / \mathrm{kg}$ de MS (Valadares Filho et al., 2010) e totalmente degradável no rúmen (Marcondes et al., 2009).

Nos últimos dez anos, as destilarias brasileiras aumentaram a produção de levedura seca de cana-de-açúcar. A busca por novas fontes de proteína para inclusão na ração animal abriu uma excelente oportunidade para o setor sucroalcooleiro. O Brasil tornou-se um dos maiores produtores e exportadores do produto, destinado principalmente à alimentação de monogástricos.

Todavia, esse produto pode apresentar algumas restrições para a alimentação de monogástricos. Altos níveis de inclusão de levedura seca de cana-de-açúcar na dieta de monogástricos pode prejudicar o desempenho dos animais, pois a baixa digestibilidade da parede celular da levedura reduz a utilização dos nutrientes da ração (Sucupira et al., 2007). O mesmo parece não ocorrer com cabras em lactação (Lima, 2010), cabras em crescimento (Lima et al., 2011) e novilhas em crescimento (Franco et al., 2010), provavelmente em razão de os animais ruminantes apresentarem flora microbiana ruminal que auxilia no processo de digestão da parece celular da levedura, e torna a levedura totalmente degradada no rúmen. Entretanto, essa característica da levedura seca pode aumentar as perdas de nitrogênio na urina e no leite e causar redução na eficiência de utilização do nitrogênio ingerido para a produção ao substituir o farelo de soja. Contudo, o maior conteúdo de carboidratos não fibrosos da levedura quando comparado ao farelo de soja poderia aumentar a eficiência de utilização da PDR pela microbiota, apresentando-se como fator de compensação. Assim, hipotetizou-se que a levedura pode substituir o farelo de soja sem afetar a eficiência de utilização dos componentes da dieta e o desempenho produtivo de vacas leiteiras.

Com o intuito de ampliar as opções de alimentos proteicos aos produtores de leite, e com isso flexibilizar os custos com alimentação dos animais ao longo do ano, amenizando os danos causados pelas oscilações sazonais do preço do farelo de soja, este trabalho foi realizado com o objetivo de avaliar a substituição do farelo de soja pela levedura na dieta de vacas lactantes.

\section{MATERIAL E MÉTODOS}

O experimento foi realizado no Departamento de Zootecnia da Universidade Federal de Viçosa, em Viçosa, Minas Gerais. Foram utilizadas 16 vacas da raça Holandês, sendo 8 vacas primíparas $(19,4 \pm 3,5 \mathrm{~kg} / \mathrm{dia}$ de leite; $520,9 \pm 31,9 \mathrm{~kg}$ de peso corporal) e 8 multíparas $(28,6 \pm 2,0 \mathrm{~kg} / \mathrm{dia}$ de leite e $608,8 \pm 43,0 \mathrm{~kg}$ de peso corporal). Os animais foram distribuídos em quatro quadrados latinos (QL) $4 \times 4$, organizados de acordo com os dias e ordem de lactação, de modo que dois QL foram constituídos por vacas primíparas e 2 por multíparas.

Foram avaliadas quatro dietas isonitrogenadas constituídas de diferentes níveis de substituição de levedura seca de cana-de-açúcar pelo farelo de soja $(0,00 ; 0,33 ; 0,67$ e $1,00 \mathrm{~kg} / \mathrm{kg})$. As dietas foram calculadas para atender às exigências nutricionais de uma vaca de $550 \mathrm{~kg}$ de peso corporal, com produção média de $27 \mathrm{~kg}$ de leite por dia, de acordo com o NRC (2001). As dietas foram constituídas por $57 \%$ de silagem de milho e $43 \%$ de concentrado, com base na MS (Tab. 1).

O experimento teve duração total de 68 dias, sendo dividido em quatro períodos de 17 dias, sendo 10 dias de adaptação e sete dias de coleta. Os animais foram manejados em baias individuais, tipo "TieStall", onde receberam alimentação na forma de ração completa após a ordenha, duas vezes ao dia ( $8 \mathrm{~h}$ e $17 \mathrm{~h})$.

Diariamente foram registradas e ajustadas as quantidades de alimentos fornecidos e as sobras (10\% em relação à matéria natural do alimento oferecido) de cada animal para a estimação do consumo. Durante os sete dias de coleta de cada período experimental, foram realizadas amostragens dos alimentos fornecidos e das sobras e, ao final, elaborou-se amostra composta representativa por animal em cada período, sendo estas armazenadas em sacos plásticos e congeladas a $-20^{\circ} \mathrm{C}$, para posteriores análises. 
Tabela 1. Ingredientes e composição química das dietas experimentais

\begin{tabular}{|c|c|c|c|c|}
\hline \multirow{2}{*}{ Ingredientes } & \multicolumn{4}{|c|}{ Níveis inclusão de levedura (\%MS) } \\
\hline & 0,0 & 33,3 & 66,6 & 100,0 \\
\hline \multicolumn{5}{|c|}{ Ingredientes $(\% \mathrm{MS})$} \\
\hline Silagem de milho & 57,00 & 57,00 & 57,00 & 57,00 \\
\hline Fubá de milho & 20,00 & 20,00 & 20,00 & 20,00 \\
\hline Farelo de trigo & 5,00 & 4,82 & 4,63 & 4,46 \\
\hline Farelo de soja & 16,23 & 10,83 & 5,40 & 0,00 \\
\hline Levedura seca & 0,00 & 5,40 & 10,83 & 16,23 \\
\hline Ureia + SA $(9: 1)^{1}$ & 0,17 & 0,33 & 0,49 & 0,64 \\
\hline Mistura mineral $^{2}$ & 1,60 & 1,62 & 1,65 & 1,67 \\
\hline \multicolumn{5}{|c|}{ Composição química (\%MS) } \\
\hline MS & 53,03 & 52,99 & 52,94 & 52,91 \\
\hline MO & 94,03 & 94,08 & 94,11 & 94,15 \\
\hline PB & 14,94 & 14,67 & 14,40 & 14,12 \\
\hline $\mathrm{EE}$ & 2,48 & 2,46 & 2,44 & 2,42 \\
\hline FDNcp & 34,22 & 33,31 & 32,40 & 31,49 \\
\hline $\mathrm{FDNi}$ & 13,86 & 13,81 & 13,76 & 13,71 \\
\hline $\mathrm{CNF}$ & 41,42 & 44,09 & 45,56 & 47,02 \\
\hline Cinzas & 5,96 & 5,93 & 5,89 & 5,85 \\
\hline
\end{tabular}

'Ureia com sulfato de amônio na proporção de 9 para $1 ;{ }^{2}$ Fosfato bicálcico $(20,12 ; 22,77 ; 23,37 ; 27,81)$, calcário calcítico $(48,88 ; 47,24 ; 45,62 ; 44,11)$, sal comum $(26,84 ; 26,66 ; 26,48 ; 26,32)$, flor de enxofre $(3,67 ; 2,87 ; 2,09 ; 1,35)$ sulfato de zinco $(0,46 ; 0,44 ; 0,42 ; 0,40)$. Os valores entre parênteses representam os teores das fontes de minerais na mistura mineral das rações concentradas com $0 ; 33,3 ; 66,6$ e 100\% de substituição do farelo de soja pela levedura, respectivamente.

No $13^{\circ}$ dia de cada período experimental, foi coletada uma amostra spot de urina de cada animal, antes da ordenha da manhã e antes da ordenha da tarde, de modo que uma amostra composta do dia e de cada animal foi subdividida em: uma amostra de diluída, constituída de $10 \mathrm{~mL}$ de urina diluídos em $40 \mathrm{~mL}$ de ácido sulfúrico 0,036 N para análises de alantoína e ácido úrico; e uma amostra concentrada, constituída de $50 \mathrm{~mL}$ de urina pura para análises de creatinina, ureia e nitrogênio. Ambas as amostras foram armazenadas em frascos plásticos a $-15^{\circ} \mathrm{C}$.

No mesmo dia, após quatro horas do fornecimento da ração, foi coletada uma amostra de sangue em cada animal, por punção na artéria coccígea, utilizando vacutainer com anticoagulante (EDTA). Após a coleta, as amostras foram imediatamente centrifugadas a 5.000rpm durante 15 minutos. Alíquotas do soro sanguíneo foram identificadas e armazenadas em tubos de $2 \mathrm{~mL}$ do tipo ependorf, em seguida, congeladas a $-20^{\circ} \mathrm{C}$, para posteriores análises de ureia.

A produção de leite foi registrada diariamente durante os sete dias de coleta de cada período experimental, mediante a soma da produção da ordenha da manhã e da tarde. Essa produção foi corrigida para $3,5 \%$ de gordura, conforme a equação proposta por Sklan et al. (1992): produção de leite corrigida (PLC) $=[(0,432+$ $0,1625 \times \%$ de gordura do leite) $\times$ (produção de leite)].

No $15^{\circ}$ e $16^{\circ}$ dias foram coletadas amostras de leite das duas ordenhas, por meio de um dispositivo acoplado ao equipamento de ordenha. Foram retiradas de cada amostra composta três alíquotas: a primeira alíquota $(50 \mathrm{~mL})$ foi acondicionada em fracos plásticos com conservante (Bronopol ${ }^{\circledR}$ ), mantidos entre $2 \mathrm{e}$ $6^{\circ} \mathrm{C}, \quad 6^{\circ} \mathrm{C}$ para determinação imediata da porcentagem de gordura, proteína bruta, lactose, sólidos totais (IDF, 2000) e contagem das células somáticas (IDF, 1995); a segunda alíquota foi desproteinizada com ácido tricloroacético $(20 \mathrm{~mL}$ de leite misturados com $10 \mathrm{~mL}$ de ácido tricloroacético a $250 \mathrm{~g} / \mathrm{L}$ ), filtrado em papelfiltro, determinando-se no filtrado o teor de nitrogênio total (Silva e Queiroz, 2002) e o restante armazenado a $-15^{\circ} \mathrm{C}$, para posterior análise de alantoína e ureia.

Nos dias 12,13,14, 15 e 16 de cada período experimental, foram coletadas amostras de fezes 
no reto, às $16 \mathrm{~h} 00,14 \mathrm{~h} 00,12 \mathrm{~h} 00,10 \mathrm{~h} 00$ e $8 \mathrm{~h} 00$ de cada dia, respectivamente, para determinação das digestibilidade das dietas.

As amostras de alimentos, sobras e fezes foram secas em estufa com ventilação forçada a $60^{\circ} \mathrm{C}$, em seguida moídas em moinho de facas (1 mm). A partir das cinco amostras de fezes moídas por animal de cada período elaborou-se uma amostra composta, com base no peso seco ao ar de cada subamostra, de modo que, para cada período experimental, obteve-se uma amostra composta de fezes.

O balanço de compostos nitrogenados (BN) foi obtido pela diferença entre o total de nitrogênio ingerido ( $\mathrm{N}$-ing) e o total de nitrogênio excretado nas fezes ( $\mathrm{N}$-fezes), na urina ( $\mathrm{N}$-urina) e no leite (N-leite).

A excreção de matéria seca fecal foi estimada utilizando a fibra insolúvel em detergente neutro indigestível (FDNi) como indicador interno. Para isso, as amostras dos alimentos, sobras e fezes foram acondicionadas em sacos F57 (Ankonß) e incubadas in situ durante 288 horas (Valente et al., 2011). O resíduo obtido após incubação foi submetido à análise de FDN (sistema ANKOM®). As estimativas de excreção fecal foram obtidas pela relação entre consumo e a concentração fecal do indicador.

A síntese de compostos nitrogenados microbianos no rúmen (Nmic, g/dia) foi calculada em função das PA (mmol/dia), por meio da equação Nmic $=(70 \times \mathrm{PA}) /(0,83 \times$ $0,116 \times 1000)$, em que 70 representa o conteúdo de $\mathrm{N}$ nas purinas (mg N/mmol); 0,83, a digestibilidade das purinas microbianas; e 0,116, a relação N-purina: $\mathrm{N}$ total nas bactérias (Chen e Gomes, 1992).

A excreção total de derivados de purina (PT) foi calculada pela soma das quantidades de alantoína e ácido úrico excretados na urina e da quantidade de alantoína excretada no leite, expressas em $\mathrm{mmol} / \mathrm{dia}$. As purinas absorvidas (PA, mmol/dia) foram calculadas a partir da excreção de PT (PT, $\mathrm{mmol} /$ dia), por meio da equação $\mathrm{PT}=0,85 \times$ $\mathrm{PA}+0,512 \times \mathrm{PV}^{0,75}$, em que 0,85 é a recuperação de purinas absorvidas como derivados de purinas (Verbic et al., 1980) e 0,512 $\times \mathrm{PV}^{0,75}$, a contribuição endógena para excreção de purinas obtidas para vacas leiteiras (González-Ronquillo et al., 2003).

O volume urinário total diário foi estimado dividindo-se as excreções urinárias diárias de creatinina pelos valores de concentração de creatinina na urina. A excreção urinária diária de creatinina foi estimada a partir da proposição de $24,05 \mathrm{mg}$ de creatinina/kg de peso corporal (Chizzotti et al., 2008).

Depois de moídas, as amostras de alimentos, sobras e fezes foram submetidas à análise para quantificação dos teores de matéria seca (MS, método $\mathrm{N}^{\mathrm{o}}$ 934,01), matéria orgânica (MO, método $\mathrm{N}^{\circ} 920.39$ ), proteína bruta (PB, método $\mathrm{N}^{\circ}$ 954.01) e extrato etéreo (EE, método $\mathrm{N}^{\circ}$ 920.39), de acordo com a AOAC (Official..., 1990). Para análise da concentração de fibra em detergente neutro (FDN), as amostras foram tratadas com alfa amilase termoestável sem uso de sulfito de sódio, corrigidas para o resíduo de cinzas (Mertens, 2002) e para o resíduo de compostos nitrogenados (Licitra et al., 1996). As análises de FDN foram realizadas em sistema Ankon ${ }^{\circledR}$, utilizando sacos de TNT (tecido-nãotecido), com dimensões de $5 \mathrm{~cm}$ x $5 \mathrm{~cm}$, mantendo-se relações médias de $14 \mathrm{mg}$ de $\mathrm{MS} / \mathrm{cm}^{2}$ de tecido e $100 \mathrm{~mL}$ de detergente neutro/g de amostra seca ao ar.

Os teores de carboidratos não fibrosos corrigidos para cinzas e proteína $\left(\mathrm{CNF}_{\mathrm{cp}}\right)$ foram calculados conforme proposto por Hall (2000) adaptado, sendo: $\mathrm{CNF}_{\mathrm{cp}}=100-[(\mathrm{PB}-\mathrm{PB}$ derivada da ureia + ureia na dieta) $+\mathrm{FDN}_{\mathrm{cp}}+\mathrm{EE}+$ Cinzas]. Os nutrientes digestíveis totais (NDT) foram calculados com adaptações ao descrito por Weis (1999), pela seguinte equação: NDT $(\mathrm{g} / \mathrm{kg})=$ PBD + FDNcpD + CNFcpD + 2,25EED, em que: $\mathrm{PBD}=$ proteína bruta digestível; FDNcpD = fibra em detergente neutro digestível; $\mathrm{CNFcpD}=$ carboidratos não-fibrosos digestíveis; e EED = extrato etéreo digestível.

As análises no plasma sanguíneo de GGT, ALT e AST foram realizadas por meio do método cinético ultravioleta otimizada (Schumann et al., 2002a,b), usando-se kits comerciais (GGT/AST/GOT Liquiform Ref. 109, Labtest Diagnóstica S.A., Lagoa Santa, Minas Gerais, Brasil). Ureia em amostras de plasma foi mensurada por meio de ensaio enzimáticocolorimétrico com kits comerciais (Urea CE Ref. 
27, Labtest Diagnóstica S.A., Lagoa Santa, Minas Gerais, Brasil). As análises de creatinina na urina foram realizadas por meio do método de ponto final com picrato e acidificante, utilizandose kits comerciais (Labtest Diagnóstica S.A., Lagoa Santa, Minas Gerais, Brasil). Ácido úrico urinário foi determinado usando método enzimático-Trinder com kits comerciais (Urea CE Ref. 27, Labtest Diagnóstica S.A., Lagoa Santa, Minas Gerais, Brasil). A concentração de alantoína nas amostras de leite (desproteinizado) e urina foi determinada por colorimetria, conforme descrito por Chen e Gomes (1992).

A quantificação do nitrogênio na urina foi feita segundo técnica descrita por Silva e Queiroz (2002).

O conjunto de dados foi analisado como quatro quadrados latinos $4 \times 4$ simultâneos, utilizando modelo misto (Littell et al., 1997) por meio do procedimento MIXED do SAS versão 9.1:

$$
\mathrm{Y}_{\mathrm{ijkl}}=\mu+\mathrm{Q}_{\mathrm{i}}+\mathrm{T}_{\mathrm{j}}+(\mathrm{P} / \mathrm{Q})_{\mathrm{ik}}+(\mathrm{V} / \mathrm{Q})_{\mathrm{il}}+\mathrm{QxT}_{\mathrm{ij}}+
$$

em que: $\mathrm{Y}_{\mathrm{ijkl}}=$ observação na vaca 1 , no período $\mathrm{k}$, submetida ao tratamento $\mathrm{j}$, no quadrado latino $\mathrm{i} ; \mu=$ média geral; $\mathrm{Q}_{\mathrm{i}}=$ efeito aleatório do quadrado latino $i$, sendo $i=1,2,3$ e $4 ; T_{j}=$ efeito fixo do nível de substituição do farelo de soja pela levedura $\mathrm{j}$, sendo $\mathrm{j}=1,2,3$ e 4 ; $(\mathrm{P} / \mathrm{Q})_{\mathrm{ik}}=$ efeito aleatório do período $\mathrm{k}$, dentro do quadrado latino $\mathrm{i}$, sendo $\mathrm{k}=1,2,3$, e 4; $(\mathrm{V} / \mathrm{Q})_{\mathrm{il}}=$ efeito aleatório da vaca 1 , dentro do quadrado latino i, sendo 1 = 1, 2, 3 e 4; QxT $_{\mathrm{ij}}=$ efeito aleatório de interação entre o quadrado latino i e o tratamento $\mathrm{j}$; ee $_{\mathrm{ijkl}}=$ erro aleatório, associado a cada observação, pressuposto NID $\left(0 ; \sigma^{2}\right)$. Os efeitos do nível de substituição do farelo de soja pela levedura foram decompostos por meio de contrastes ortogonais para efeitos de ordem linear, quadrático e cúbico. Em razão da ausência de efeitos de ordem cúbica, os mesmos foram suprimidos dos resultados. Adotou-se nível de 0,05 de probabilidade para o erro tipo I. Os resultados foram apresentados como médias dos quadrados mínimos.

\section{RESULTADOS}

A substituição do farelo de soja pela levedura não afetou os consumos de $\mathrm{MS}(\mathrm{P}=0,626)$, MO $(\mathrm{P}=0,612)$, EE $(\mathrm{P}=0,209)$, FDNi $(\mathrm{P}=0,194)$ e NDT $(\mathrm{P}=0,701)$, mas reduziu linearmente $\mathrm{o}$ consumo de $\mathrm{PB}(\mathrm{P}=0,019)$ e FDNcp $(\mathrm{P}=0,005)$, e aumentou linearmente o consumo de CNF $(\mathrm{P}=0,007)($ Tab. 2).

Não houve efeito de tratamento sobre os coeficientes de digestibilidade da MS $(\mathrm{P}=0,448)$, MO ( $\mathrm{P}=0,435), \mathrm{PB}(\mathrm{P}=0,247), \mathrm{CNF}(\mathrm{P}=0,188)$ e no teor de NDT $(\mathrm{P}=0,472)$, porém os coeficientes de digestibilidade do FDNcp $(\mathrm{P}=0,05)$ e do $\mathrm{EE}$ $(\mathrm{P}=0,009)$ decresceram linearmente com a substituição do farelo de soja pela levedura nas dietas experimentais (Tab.2).

\begin{tabular}{|c|c|c|c|c|c|c|c|}
\hline \multirow{2}{*}{ Itens } & \multicolumn{4}{|c|}{ Níveis inclusão de levedura (\% MS) } & \multicolumn{2}{|c|}{ P-Valor } & \multirow{2}{*}{ SE } \\
\hline & 0,0 & 33,3 & 66,6 & 100,0 & $\mathrm{~L}$ & Q & \\
\hline \multicolumn{8}{|c|}{ Consumo (kg/dia) } \\
\hline MS & 18,06 & 18,53 & 18,00 & 18,25 & 0,945 & 0,626 & 0,329 \\
\hline MO & 16,97 & 17,43 & 16,93 & 17,16 & 0,975 & 0,612 & 0,310 \\
\hline PB & 2,69 & 2,71 & 2,56 & 2,54 & 0,019 & 0,627 & 0,048 \\
\hline $\mathrm{EE}$ & 0,45 & 0,46 & 0,44 & 0,44 & 0,209 & 0,580 & 0,007 \\
\hline FDNcp & 6,38 & 6,41 & 6,09 & 6,01 & 0,005 & 0,497 & 0,115 \\
\hline $\mathrm{FDNi}$ & 1,94 & 2,06 & 1,96 & 1,95 & 0,647 & 0,194 & 0,611 \\
\hline $\mathrm{CNF}$ & 7,47 & 7,93 & 7,96 & 8,35 & 0,007 & 0,694 & 0,144 \\
\hline NDT & 12,10 & 12,00 & 12,01 & 12,26 & 0,976 & 0,701 & 0,269 \\
\hline \multicolumn{8}{|c|}{ Digestibilidade aparente $(\%)$} \\
\hline MS & 67,03 & 64,78 & 66,49 & 66,28 & 0,659 & 0,448 & 1,300 \\
\hline MO & 68,38 & 66,31 & 68,09 & 68,00 & 0,784 & 0,435 & 1,234 \\
\hline PB & 70,15 & 64,88 & 68,44 & 67,51 & 0,404 & 0,247 & 2,047 \\
\hline $\mathrm{EE}$ & 75,11 & 68,27 & 71,74 & 63,16 & 0,009 & 0,617 & 2,306 \\
\hline FDNcp & 53,27 & 50,51 & 50,63 & 49,19 & 0,050 & 0,668 & 1,723 \\
\hline $\mathrm{CNF}$ & 80,43 & 79,93 & 81,67 & 82,65 & 0,188 & 0,571 & 1,058 \\
\hline NDT & 66,88 & 64,97 & 67,01 & 66,89 & 0,991 & 0,472 & 1,199 \\
\hline
\end{tabular}

Tabela 2. Consumo e digestibilidade aparente das dietas 
Não foi verificado efeito linear ou quadrático dos tratamentos sobre as excreções de alantoína na urina e no leite $(\mathrm{P}=0,326)$, ácido úrico $(\mathrm{P}=0,520)$, purinas totais $(\mathrm{P}=0,336)$, nitrogênio microbiano
$(\mathrm{P}=0,331)$, proteína microbiana $(\mathrm{P}=0,335)$, eficiência de síntese microbiana $(\mathrm{P}=0,363) \mathrm{e}$ utilização do nitrogênio ( $\mathrm{P}=0,170)$ (Tab. 3).

Tabela 3. Médias diárias das excreções de purinas, síntese de nitrogênio e proteína microbiana, eficiência de síntese microbiana e eficiência de utilização do nitrogênio

\begin{tabular}{|c|c|c|c|c|c|c|c|}
\hline \multirow{2}{*}{ Itens } & \multicolumn{4}{|c|}{ Níveis inclusão de levedura (\% MS) } & \multicolumn{2}{|c|}{ P-Valor } & \multirow{2}{*}{ SE } \\
\hline & 0,0 & 33,3 & 66,6 & 100,0 & $\mathrm{~L}$ & $\mathrm{Q}$ & \\
\hline $\mathrm{ALAN}^{1} \mathrm{mmol} / \mathrm{dia}$ & 308,9 & 325,35 & 331,23 & 357,17 & 0,326 & 0,933 & 22,64 \\
\hline ACU mmol/dia & 5,75 & 4,77 & 5,31 & 5,27 & 0,638 & 0,520 & 0,450 \\
\hline DPT mmol/dia & 313,84 & 330,13 & 336,54 & 362,45 & 0,336 & 0,945 & 21,42 \\
\hline NMIC g/dia & 203,83 & 215,49 & 220,02 & 238,01 & 0,331 & 0,951 & 15,61 \\
\hline PBMIC g/dia & 1,27 & 1,34 & 1,37 & 1,49 & 0,335 & 0,955 & 1,347 \\
\hline EMIC gPB/NDT & 104,95 & 111,66 & 114,16 & 121,53 & 0,363 & 0,735 & 10,80 \\
\hline EUN & 48,22 & 49,40 & 54,25 & 58,09 & 0,170 & 0,863 & 3,65 \\
\hline
\end{tabular}

ALAN: alantoína; ACU: ácido úrico; DPT: derivados de purinas totais; NMIC: nitrogênio microbiano; EMIC: eficiência de síntese microbiana (g PB / kg NDT); EUN: eficiência de utilização do nitrogênio (g PBmic/N ingerido); ${ }^{1}$ soma da excreção de alantoína na urina e no leite.

Observou-se efeito linear decrescente para as concentrações de nitrogênio ureico no plasma $(\mathrm{P}=0,05)$ e no leite $(\mathrm{P}=0,006)$ e para as excreções diárias de nitrogênio ureico no leite $(\mathrm{P}=0,006)$, porém não foi observado efeito das dietas experimentais sobre a excreção diária de compostos nitrogenados totais no leite $(\mathrm{P}=0,268)$ e na urina $(\mathrm{P}=0,261)$, nitrogênio ureico na urina $(\mathrm{P}=0,340)$ e balanço de nitrogênio $(\mathrm{P}=0,263$; Tab.4).

Tabela 4. Médias obtidas para as concentrações de nitrogênio ureico no plasma e no leite e excreções de $\mathrm{N}$ total no leite, de nitrogênio ureico no leite, de $\mathrm{N}$ urinário total e de nitrogênio ureico na urina para as diferentes dietas experimentais

\begin{tabular}{|c|c|c|c|c|c|c|c|}
\hline \multirow[b]{2}{*}{ Itens } & \multicolumn{4}{|c|}{ Níveis inclusão de levedura (\% MS) } & \multicolumn{2}{|c|}{ P-valor } & \multirow[b]{2}{*}{ SE } \\
\hline & 0,0 & 33,3 & 66,6 & 100,0 & $\mathrm{~L}$ & Q & \\
\hline \multicolumn{8}{|c|}{ Concentrações (mg/dL) } \\
\hline NUP & 22,97 & 20,04 & 18,90 & 19,74 & 0,050 & 0,118 & 1,23 \\
\hline NUL & 20,05 & 17,56 & 17,43 & 16,71 & 0,006 & 0,251 & 0,953 \\
\hline \multicolumn{8}{|c|}{ Excreções diárias (g/dia) } \\
\hline NL & 125,79 & 129,41 & 127,61 & 124,38 & 0,671 & 0,268 & 4,33 \\
\hline NUL & 5,14 & 4,38 & 4,42 & 4,10 & 0,006 & 0,337 & 0,321 \\
\hline NU & 110,0 & 118,0 & 135,0 & 128,0 & 0,261 & 0,701 & 16,22 \\
\hline NUU & 91,98 & 69,59 & 70,89 & 72,84 & 0,340 & 0,353 & 11,52 \\
\hline $\mathrm{BN}$ & 36,27 & 25,21 & 13,27 & 19,86 & 0,263 & 0,453 & 15,13 \\
\hline
\end{tabular}

NUP: nitrogênio ureico no plasma; NUL: nitrogênio ureico no leite; NL: compostos nitrogenados totais no leite; NU: nitrogênio urinário total; NUU: nitrogênio ureico na urina; BN: balanço de nitrogênio.

Diferenças estatísticas entre os tratamentos não foram observadas para a produção de leite $(\mathrm{P}=0,471)$, produção de leite corrigida para $3,5 \%$ de gordura $(\mathrm{P}=0,471)$, teores no leite $(\mathrm{P}=0,608)$ e produção diária de gordura $(\mathrm{P}=0,693)$, teores no leite $(\mathrm{P}=0,319)$ e produção diária de proteína bruta $(\mathrm{P}=0,234)$, teores no leite $(\mathrm{P}=0,085)$ e produção diária de lactose $(\mathrm{P}=0,290)$, teores no leite de sólidos totais $(\mathrm{P}=0,640)$ e eficiência de utilização da matéria seca $(\mathrm{P}=0,384)$. No entanto, houve efeito linear crescente para relação de nitrogênio no leite e nitrogênio ingerido $(\mathrm{P}=0,016$; Tab. 5). 
Levedura seca integral...

Tabela 5. Produção, composição centesimal do leite, eficiência de utilização da matéria seca e nitrogênio dos animais que receberam as dietas experimentais

\begin{tabular}{|c|c|c|c|c|c|c|c|}
\hline \multirow[t]{2}{*}{ Itens } & \multicolumn{4}{|c|}{$\begin{array}{c}\text { Níveis inclusão de levedura } \\
(\% \mathrm{MS})\end{array}$} & \multicolumn{2}{|c|}{ P-valor } & \multirow[t]{2}{*}{ SE } \\
\hline & 0,0 & 33,3 & 66,6 & 100,0 & $\mathrm{~L}$ & $\mathrm{Q}$ & \\
\hline PL (kg/dia) & 25,05 & 25,15 & 24,86 & 24,54 & 0,532 & 0,471 & 0,563 \\
\hline PLC (kg/dia) & 25,06 & 25,16 & 24,88 & 24,55 & 0,532 & 0,471 & 0,563 \\
\hline Gordura (\%) & 3,74 & 3,68 & 3,54 & 3,60 & 0,608 & 0,931 & 0,128 \\
\hline Gordura(kg/dia) & 0,93 & 0,93 & 0,86 & 0,90 & 0,693 & 0,947 & 0,043 \\
\hline $\mathrm{PB}(\%)$ & 3,18 & 3,26 & 3,23 & 3,25 & 0,391 & 0,319 & 0,272 \\
\hline PB (kg/dia) & 0,80 & 0,82 & 0,80 & 0,80 & 0,662 & 0,234 & 0,019 \\
\hline LACT (\%) & 4,14 & 4,18 & 4,20 & 4,13 & 0,724 & 0,085 & 0,035 \\
\hline LACT (kg/dia) & 1,03 & 1,05 & 1,03 & 1,00 & 0,581 & 0,290 & 0,027 \\
\hline ST $(\%)$ & 12,21 & 12,29 & 12,14 & 12,15 & 0,671 & 0,640 & 0,112 \\
\hline kg leite/CMS & 1,37 & 1,36 & 1,37 & 1,33 & 0,384 & 0,394 & 0,022 \\
\hline $\mathrm{N}$ leite/ $\mathrm{N}$ ingerido & 28,57 & 29,54 & 30,70 & 30,51 & 0,016 & 0,250 & 0,580 \\
\hline
\end{tabular}

\section{DISCUSSÃO}

O consumo e a digestibilidade da matéria seca e nutrientes são parâmetros fundamentais para a determinação do desempenho animal, pois regulam o ingresso de nutrientes necessários ao atendimento das exigências de mantença e produção animal. Desse modo, a ausência de diferença estatística do efeito dos tratamentos sobre o consumo de MS, MO, EE, FDNi, NDT, digestibilidade aparente da MS, MO, PB, CNF e NDT são indicadores de que a levedura é um ingrediente proteico que não apresenta restrições ao consumo total de vacas leiteiras. Entretanto, a redução linear do consumo de PB, observada com o aumento da inclusão de levedura seca na dieta, pode ter ocorrido em razão de limitações físicas do ingrediente, uma vez que a levedura é higroscópica, característica que a torna altamente aglutinante, formando aglomerados no fundo dos cochos, dificultando o acesso dos animais a parte do concentrado fornecido e permitindo um maior consumo de silagem que apresenta menor teor proteico. A característica higroscópica da levedura pode ser um limitante ao uso comercial desse produto em maiores quantidades do que as apresentadas neste trabalho; entretanto, esse efeito deve ser melhor compreendido, uma vez que não foram encontrados relatos semelhantes na literatura.

A redução linear do consumo de FDNcp e aumento do consumo de CNF não influenciaram o consumo total de MS, e ocorreram em razão do menor teor de FDNcp e maior teor de CNF da levedura em relação ao farelo de soja. No entanto, o maior consumo de CNF proporcionou a redução linear da digestibilidade da FDNcp, em razão de possíveis mudanças na taxa de fermentação da fibra da dieta, proporcionada por variações no $\mathrm{pH}$ ruminal de correntes do acúmulo de ácidos graxos voláteis oriundos da fermentação de fontes de carboidratos rapidamente degradáveis (Richard e Mertens, 1992 apud Van Soest, 1994). Quanto à redução da digestibilidade do EE, tendo em vista o reduzido valor de gordura em rações de ruminantes e considerando-se ainda o menor conteúdo de extrato etéreo da levedura quando comparado ao farelo de soja, estes resultados perdem muito em importância prática.

Franco et al. (2010) também não observaram diferença na ingestão de MS quando novilhas foram alimentadas com os mesmos níveis de inclusão de levedura deste trabalho. Estudo desenvolvido por Lima (2010) demonstrou que a substituição total do farelo de soja pela levedura em dietas de cabras em lactação não apresentou efeito significativo sobre o consumo de MS, MO, PB, FDN e NDT dos animais. Lima et al. (2011) também não observaram diferença na ingestão de MS, MO e PB quando cabritos foram alimentados com dieta contendo $100 \%$ de substituição do farelo de soja pela levedura; porém, neste trabalho, verificou-se redução no consumo de EE e FDN.

Lima et al. (2011) verificaram que a substituição total do farelo de soja por levedura na dieta de 
cabritos na fase de terminação proporcionou aumento da digestibilidade da MS, MO, PB, redução da digestibilidade do $E E$ e não apresentou efeito sobre a FDN. Redução linear na digestibilidade de EE também foi observada no trabalho de Freitas et al. (2009), que avaliaram a inclusão de $0,25,50,75$ e $100 \%$ de levedura na dieta de cabritos. Lima (2010) avaliou a inclusão de $100 \%$ de levedura em substituição do farelo de soja na dieta de cabras leiteiras e observou aumento da digestibilidade da MS e MO, porém não obteve efeito significativo sobre a digestibilidade da PB, EE e FDN.

A estimativa da síntese de proteína microbiana é fundamental para avaliação da nutrição proteica de vacas leiteiras, pois dietas que alteram a produção de proteína microbiana afetam a quantidade e a qualidade da proteína que chega ao intestino delgado. Neste trabalho, não foi observada diferença estatística para a produção e eficiência de proteína microbiana. No entanto, quando avaliados os valores apresentados na Tabela 3, verifica-se que houve uma tendência de aumento da produção e eficiência de síntese microbiana para os tratamentos com maior nível de inclusão de levedura, demonstrando que a alta taxa de proteína degradável no rúmen (PDR), associada à maior concentração de carboidrato degradável proveniente da levedura, afetou a taxa de fermentação ruminal.

A diferença observada na concentração de nitrogênio ureico no plasma e no leite entre os tratamentos pode ser atribuída à diferença observada no consumo de proteína bruta e carboidratos não fibrosos (CNF) dos animais que receberam as dietas com maior nível de inclusão de levedura. Godden et al. (2001) correlacionaram a dieta de rebanhos comerciais com o NUL e verificaram correlação negativa entre a concentração de NUL e a porcentagem de CNF na dieta, em razão de essa fração do alimento ter alta disponibilidade de carboidratos rapidamente degradáveis no rúmen, o que favorece a utilização do nitrogênio amoniacal pelos microrganismos ruminais.

Todos os fatores que interferem na concentração de ureia no sangue também interferem na concentração de ureia no leite, por isso existe uma alta correlação entre essas duas variáveis (Oliveira et al., 2000). A concentração de nitrogênio excretado na urina também apresenta correlação com o nitrogênio ureico do plasma e do leite; porém, neste trabalho, não foi verificado efeito significativo das dietas experimentais sobre a excreção diária de nitrogênio ureico na urina e nitrogênio total na urina, provavelmente em razão de a excreção de compostos nitrogenados na urina serem influenciados por diversos fatores, entre eles o volume urinário, que podem ter contribuído para a ausência de significância dessa variável. Existe uma menor quantidade de fatores que interferem na concentração de ureia no leite, por isso Duinkerken et al. (2005) destacam essa variável como sendo um melhor indicador da eficiência de utilização dos compostos nitrogenados da dieta.

O balanço de nitrogênio positivo para todas as dietas experimentais sugere que o consumo de proteína bruta supriu as exigências de mantença e produção de todos os animais submetidos às quatro dietas experimentais.

A ausência de significância dos tratamentos sobre a produção de leite pode ser explicada pela ausência de resposta na ingestão de MS (Chizzotti et al., 2007). Salienta-se que a resposta produtiva dos animais é em função do consumo, da digestibilidade e do metabolismo dos nutrientes, porém o consumo parece ser a variável mais importante, que determina cerca de 60 a $90 \%$ da variação observada na ingestão de energia digestível entre animais e dietas (Reid, 1961).

A eficiência de utilização do nitrogênio dietético para a produção de proteína do leite apresentou efeito linear crescente, em razão de os tratamentos terem apresentado efeito linear decrescente sobre o consumo de PB, sem, no entanto, apresentar efeito sobre a porcentagem de proteína no leite. Com isso, os animais que receberam as dietas com maior quantidade de levedura foram mais eficientes em utilizar $\mathrm{o}$ nitrogênio dietético para a produção de proteína no leite.

\section{CONCLUSÃO}

A levedura seca pode substituir em $100 \%$ o farelo de soja na alimentação de vacas lactantes, com média de produção diária de $25 \mathrm{~kg}$ de leite, recebendo dietas à base de silagem de milho. 


\section{REFERÊNCIAS}

OFFICIAL Methods of Analysis - AOAC, $15^{\text {th }}$ ed. AOAC International, Arlington.1990.

CHEN, X.B.; GOMES, M.J. Estimation of microbial protein supply to sheep and cattle based on urinary excretion of purine derivatives - an overview of the technical details. International Feed Research Unit. Aberdeen, UK: Rowett Research Institute (Occasional publication), 1992. 21p.

CHIZZOTTI, M.L.; VALADARES FILHO, S.D.C.; VALADARES, R.F.D. et al. Consumo, digestibilidade e excreção de ureia e derivados de purinas em vacas de diferentes níveis de produção de leite. Rev. Bras. Zootec., v.36, p.138-146, 2007.

CHIZZOTTI, M.L.; VALADARES FILHO, S.D.C.; VALADARES, R.F.D. et al. Determination of creatinine excretion and evaluation of spot urine sampling in Holstein cattle. Livest. Sci., v.113, p.218-225, 2008.

DUINKERKEN, G.V.; ANDRÉ, G.; SMITS, M.C.J. et al. Effect of rumen-degradable protein balance and forage type on bulk milk urea concentration and emission of ammonia from dairy cow houses. J. Dairy Sci., v.88, p.10991112, 2005.

FRANCO, M.O.; CAMPOS, J.M.S.; GIONBELLI, M.P. et al. Desempenho de novilhas leiteiras, puras e mestiças, em crescimento, alimentadas com levedura seca de cana-de-açúcar. In: REUNIÃO ANUAL DA SOCIEDADE BRASILEIRA DE ZOOTECNIA, 47., 2010. Salvador. Anais...Salvador: UFBA, 2010. 1 CD ROM. (Resumo).

FREITAS, H.S.; ALCADE, C.R.; LIMA, L.S. et al. Digestibilidade total em cabritos recebendo rações contendo levedura seca. In. CONGRESSO INTERNACIONAL SOBRE USO DA LEVEDURA NA ALIMENTAÇÃO ANIMAL, 1., 2009, Campinas. Anais... Campinas: Congresso Brasileiro de Nutrição Animal, 2009. p.1-4 (Resumo).

GODDEN, S.M.; LISSEMORE, K.D.; KELTON, D.F et al. Relationships between milk urea concentrations and nutricional management, production, and economic variables in Ontario dairy herds. J. Dairy Sci., v.84, p.1128-1139, 2001.
GONZÁLEZ-RONQUILLO, M.; BALCELLS， J.; GUADA, J.A.; VICENTE, F. Purine derivative excretion in dairy cows: Endogenous excretion and the effect of exogenous nucleic acid supply. J. Dairy Sci., v.86, p.1282-1291, 2003.

HALL, M.B. Calculation of Non-structural Carbohydrate Content of Feeds that Contain Non-protein Nitrogen. University of Florida, P.A-25 (Bulletin 339, April 2000).

IDF. International IDF Standard 141C:2000: Whole milk - determination of milk fat, protein and lactose content. Guidance on the operation of mid-infrared instruments. Brussels 2000, $15 f$.

IDF. International IDF Standard 148A:1995: Milk - Enumaration of somatic cell. Brussels, 1995 (a), 8f.

LICITRA, G.; HERNANDEZ, T.M.; VAN SOEST, P.J. Standardization of procedures for nitrogen fractionation of ruminant feeds. Anim. Feed Sci. Technol., v.57, p.347-358, 1997.

LIMA, L.S. Produção de leite de cabra $e$ fermentação ruminal utilizando rações com levedura seca, 2010. 65f. Dissertação (Mestrado em Zootecnia) - Universidade Estadual de Maringá, Maringá.

LIMA, L.S.; ALCALDE, C.R.; MACEDO, F.A.F. et al. Sugar cane dry yeast in feeding for growing and finishing goat kids. Rev. Bras. Zootec., v.40, p.168-173, 2011.

LITTELL, R.C.; HENRY, P.R.; LEWIS, A.J. et al. Estimation of relative bioavailability of nutrients using SAS procedures. J. Anim. Sci., v.75, p.2672-2683, 1997.

MARCONDES, M.I.; VALADARES FILHO, S.C.; DETMANN, E. et al. Degradação ruminal e digestibilidade intestinal da proteína bruta de alimentos para bovinos. Rev. Bras. Zootec., v.38, p.2247-2257, 2009.

MERTENS, D.R. Gravimetric determination of amylase-treated neutral detergent fiber in feeds with refluxing in beaker or crucibles: collaborative study. J. AOAC Int., v.85, p.12171240, 2002.

NUTRIENT requirements of dairy cattle - NRC. 7th.ed. Washington, DC: National Academy Press, 2001. 362p. 
OLIVEIRA, A.S.; CAMPOS, J.M.S.; VALADARES FILHO, S.C. et al. Substituição do milho pela casca de café ou de soja em dietas para vacas leiteiras: comportamento ingestivo, concentração de nitrogênio uréico no plasma e no leite, balanço de compostos nitrogenados e produção de proteína microbiana. Rev. Bras. Zootec., v.36, p.205-215, 2007.

REID, J.T. Problems of feed evaluation related to feeding dairy cows. J. Dairy Sci., v.11, p.21222133,1961 .

SANTOS, G.D. Perspectivas brasileira e mundial da produção de leveduras. In: CONGRESSO INTERNACIONAL SOBRE USO DA LEVEDURA NA ALIMENTAÇÃO ANIMAL, 1., 2009, Campinas. Anais... Campinas: Congresso Brasileiro de Nutrição Animal, 2009. p.1-4. (Resumo).

SCHUMANN, G.; BONORA, R.; CERIOTTI, F. et al. IFCC primary reference procedures for the measurement of catalytic activity concentrations of enzymes at $37{ }^{\circ} \mathrm{C}$. International Federation of Clinical Chemistry and Laboratory Medicine. Part 4. Reference procedure for the measurement of catalytic concentration of alanine aminotransferase. Clin.Chem. Lab. Med., v.40, p.718-724, 2002a.

SCHUMANN, G.; BONORA, R.; CERIOTTI, F. et al. IFCC primary reference procedures for the measurement of catalytic activity concentrations of enzymes at $37{ }^{\circ} \mathrm{C}$. International Federation of Clinical Chemistry and Laboratory Medicine. Part 5. Reference procedure for the measurement of catalytic concentration of aspartate aminotransferase. Clin. Chem. Lab. Med., v.40, p.725-733, $2002 b$.
SKLAN, D.; ASHKENNAZI, R.; BRAUN, A. et al. Fatty acids, calcium soaps of fatty acids, and cottonseeds fed to high yielding cows. J. Dairy Sci., v.75, p.2463-2472, 1992.

SILVA, D.J.; QUEIROZ, A.C. Análise de alimentos: métodos químicos e biológicos. 3.ed. Viçosa: UFV, 2002. 235p.

SUCUPIRA, F.S.; FUENTES, M.F.F.; FRETS, E.R. et al. Alimentação de codornas de postura com rações contendo levedura de cana-deaçúcar. Rev. Cienc. Rural, v.37, p.528-532, 2007.

VERBIC, J.; CHEN, X.B.; MCLEOD, N.A.; ORSKOV, E.R. Excretion of purine derivatives by ruminants.Effect of microbial nucleic acid infusion on purine derivative excretion by steers. J. Agric. Sci. Camb., v.114, p.243-248, 1980.

VALADARES FILHO, S.C.; MACHADO, P.A.S.; CHIZZOTTI, M.L. et al. Tabelas brasileiras de composição de alimentos para bovinos. 3. ed. Viçosa: Universidade Federal de Viçosa, Departamento de Zootecnia, 2010. 329p.

VALENTE, T.N.P.; DETMANN, E.; QUEIROZ, A.C. et al. Evaluation of ruminal degradation profiles of forages using bags made from different textiles. R. Bras. Zootec., v.40, p.25652573, 2011.

VAN SOEST, P.J. Nutritional ecology of the ruminant. 2.ed. London: Comstock Publishing Associates, 1994. 476p.

WEISS, W.P. Energy prediction equations for ruminant feeds. In: CORNELL NUTRITION CONFERENCE FOR FEED MANUFACTURERS, 61., 1999, Proceedings... Ithaca: Cornell University, 1999. p.176-185. 